\title{
A Promising but Challenging Strategy for Cancer Treatment: Disruption of Myc-Max Heterodimerization
}

\section{Hyojin Kim ${ }^{1}$, Minjin Yoo $^{2}$ and Kwan-Young Jung ${ }^{2,3 *}$}

${ }^{1}$ Department of Chemistry, Sogang University, 5 Baekbeom-ro, Mapo-gu, Seoul 04107, Republic of Korea

${ }^{2}$ Department of Medicinal Chemistry and Pharmacology, University of Science \& Technology, Daejeon 34113, Republic of Korea

${ }^{3}$ Bio \& Drug Discovery Division, Korea Research Institute of Chemical Technology, Daejeon 34114, Republic of Korea

\section{Abstract}

c-Myc (Myc) is oncoprotein and nuclear transcription factor which plays a crucial role in several central cellular processes, involving cell proliferation, transformation, inhibition of differentiation and apoptosis. These functions result from the transcriptional activity of Myc. To be a functional form, Myc protein binds to the Max which recruits the E-box. Dysregulated over-expression of Myc is observed in many human malignancies including breast cancer, small-cell lung cancer, osteosarcomas, glioblastomas, and myeloid leukemias. Therefore, inhibition of the Myc-Max dimerization is a promising strategy for anticancer therapy. In this review, we summarize the Myc-Max disruption by small molecules targeting the oncogene. These information will contribute to the research and development of Myc-targeted smallmolecule drugs.

\section{Publication History:}

Received: May 16, 2016 Accepted: July 16, 2016

Published: July 18, 2016

\section{Keywords:}

Myc, Max, Small molecule, Cancer, Pharmacophore

\section{Introduction}

Cancer is one of the most feared of all human diseases, and the need to develop high-efficacy and low-toxicity cancer drugs is an important field that is being actively studied. Consecutively occurring impairments to DNA result in activation of several oncogenes, including Myc. In contrast, tumor suppressor genes are inactivated, which affects the DNA repair system and disrupts normal apoptosis regulation pathways [1]. Myc is a transcriptional regulator with a basic helix-loop-helix leucine zipper (bHLH-ZIP) domain that becomes functional after dimerization with its obligate partner protein, Max [2]. The coiled-coil structure of the Myc-Max heterodimer has a palindromic E-box sequence 5'-CACGTG-3' that recruits the DNA [3]. Myc interacts with target gene promoters to stimulate or suppress transcriptional activity [4]. Overexpression of Myc is involved in transformation processes, including proliferation, apoptosis, differentiation, and metabolism [5]; however, dysregulation of Myc is involved in the vast majority of human cancers such as lung, pancreatic, and colorectal cancer in addition to leukemia and lymphomas [6]. Because of its multiple functions, there has been concern that targeting Myc-Max/DNA interactions for drug development would result in undesirable side effects. However, studies of the dominantnegative Myc mutant, omomyc, have suggested that pharmacological inhibition of Myc results in gentle and reversible effects on normal, quick-proliferating tissues $[7,8]$. Together, these studies suggest that Myc inhibition by direct disruption of Myc-Max/DNA or subsidiary inhibition of Myc using BET bromodomain inhibitors [9-11] could be a feasible restorative method and is on the cutting edge of new and focused anticancer drug development. The favored methodology to identify possible Myc inhibitors has been to measure obstruction of Myc-Max dimerization; however, protein-protein interactions (PPIs) within the large surface area $\left(\sim 3,200 \AA^{2}\right)$ and many binding pockets that have not yet been identified are primary hindrances [3]. Despite these difficulties, an absolute amino acid substitution may completely disturb the dimerization of Myc with Max [3]. Here, we provide evidence for the principle that a high-affinity ligand attached to the interactional surface may provide additional disruption of Myc-Max dimerization.

\section{Myc Inhibitors}

Procownik et al. applied a yeast two-hybrid assay systemtoa library of 10,000 chemicals to discover 10058-F4, a rhodanine scaffoldcontaining small molecule that is a potent Myc-Max inhibitor [12]. An HL60 human promyelocytic leukemia cell line over-expressing Myc was then used to test the efficacy of 10058-F4. Myc-Max/DNA binding was interrupted by $10058-\mathrm{F} 4$, with an $\mathrm{IC}_{50}$ value of $49 \mu \mathrm{M}$. Considering the strong protein-protein interactions involved in MycMax/DNA binding, including strong hydrogen bonding, electrostatic interactions, and $\pi-\pi$ interactions, we suggest that these results are remarkable. From the perspective of medicinal chemists, small molecules contain many positive attributes, including the ability to substitute several functional groups on the scaffold. In the work by Procownik et al., several substituents on the 4-ethylphenyl moiety of 10058-F4 were introduced, including 4-chlorophenyl; cyclohexyl; 3,4-dihydroxyphenyl; and 4-isopropylphenyl moieties; however, substituted compounds have not improved the activity of 10058-F4. Fixing a 4-ethylphenyl group on the left position of 10058-F4 and then modifying the right side of the rhodanine core did not significantly improve activity. In a follow-up modification, $\mathrm{N}$-methylpiperidinyl functionalization of the rhodanine $\mathrm{NH}$ group followed by substitution with an isopropylphenyl ring resulted in the introduction of $28 \mathrm{RH}-$ NCN-1 and inhibition of Myc binding to DNA that is equivalent to $10058-\mathrm{F} 4$ in an in vitro system. However, the inhibitory activity increased 2 -fold in HL60 whole cells, with an $\mathrm{IC}_{50}=29 \mu \mathrm{M}$. Both 28RH-NCN-1 and 10058-F4 demonstrated concentration-dependent inhibition of Myc-Max heterodimer formation in HL60 cells that was associated with a decrease in cell proliferation [13].

Work done in the laboratory of Metalloet al. from Georgetown University elucidated the interruption mode of 10058-F4 and 10074G5 to their target proteins Myc-Max using NMR dynamic structures. 10058-F4 binds $\mathrm{Myc}_{402-412}$ sequences, whereas $10074-\mathrm{G} 5$ binds

"Corresponding Author: Dr. Kwan-Young Jung, Bio \& Drug Discovery Division, Korea Research Institute of Chemical Technology, Daejeon 34114, Republic of Korea, Tel: +82-42-860-7692; E-mail: krjeong@krict.re.kr

Citation: Kim H, Yoo M, Jung KY (2016) A Promising but Challenging Strategy for Cancer Treatment: Disruption of Myc-Max Heterodimerization. Int $\mathrm{J}$ Clin Pharmacol Pharmacother 1: 114. doi: http://dx.doi.org/10.15344/2016/ijccp/114

Copyright: @ $2016 \mathrm{Kim}$ et al. This is an open-access article distributed under the terms of the Creative Commons Attribution License, which permits unrestricted use, distribution, and reproduction in any medium, provided the original author and source are credited. 
Citation: Kim H, Yoo M, Jung KY (2016) A Promising but Challenging Strategy for Cancer Treatment: Disruption of Myc-Max Heterodimerization. Int J Clin Pharmacol Pharmacother 1: 114. doi: http://dx.doi.org/10.15344/2016/ijccp/114

Page 2 of 4

$\mathrm{Myc}_{363-381}$ sequences [14]. In addition, the nitro group and furazan core of 10074-G5 could interact with the positively charged amino acid residues, Arg 372 and Arg 362, while the biphenyl group has $\pi-\pi$ interactions with a hydrophobic region composed of Phe375, Ile381, and the side chain methylene moiety of Arg 378. The discovery of two free tying sites, each comprising over 10 residues inside a bHLH-ZIP domain that is 84 amino acids in length, suggests that sites capable of specific small-molecule binding are universal in intrinsically disordered proteins [14] (Table 1). bromophenyl, and piperidinyl resulted in no or weak inhibition activity; however, introducing a carboxylic acid at the para-position on the phenyl ring (compound JY-3-094) increased the potency to five times of that observed for the lead compound, with an $\mathrm{IC}_{50}$ of $33 \mu \mathrm{M}$ for disruption of Myc-Max heterodimers [15]. In a follow-up paper to their early work, Fletcher et al. introduced ester functionality to the para-position of JY-3-094, which has poor cell permeability. The prodrug molecule JY-3-094 and its derivatives warrant further development of small-molecule Myc-Max inhibitors [16]. Recently,

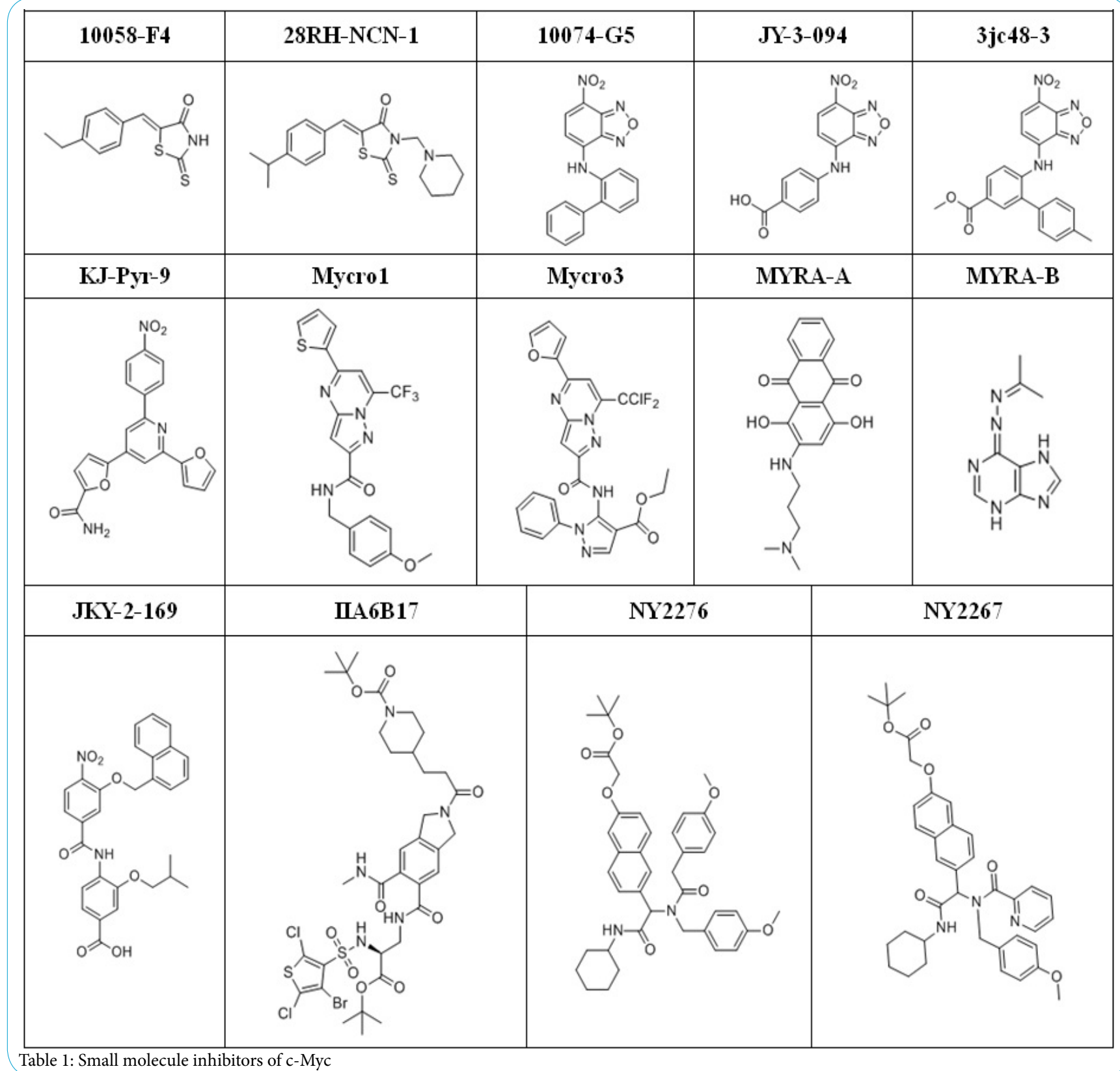

Work by Fletcher et al. identified the Myc inhibitor pharmacophore, 10074-G5, through a structure-activity relationship (SAR) study. 10074-G5 is composed of three distinct moieties, including a nitro functional group on the top subunit, a benzofurazan core, and a 2 -aminobiphenyl group. Reduction of the nitro group to an amine and introduction of several functional groups on the $\mathrm{NH}_{2}$-nitrogen atom resulted in loss of inhibitory activity. Modification of the biphenyl moiety to phenyl, hydroxyphenyl, cyclohexyl, methoxyphenyl,
Fletcher et al. disclosed the active and stable (half-life in cell $>17 \mathrm{~h}$ ) Myc-Max inhibitor 3jc48-3 [17], which has an additional hydrophobic group on the phenyl ring of the prodrug molecule JY-3-094. Treatment of HL60 and Daudi cells with 3jc48-3 repressed proliferation with single-digit micromolar $\mathrm{IC}_{50}$ values in a way that corresponded to the intracellular interruption of Myc-Max heterodimers. In addition, Fletcher et al. developed a novel and direct Myc inhibitor, JKY-2169 , that is distinctly different from their previous compounds. This 
Citation: Kim H, Yoo M, Jung KY (2016) A Promising but Challenging Strategy for Cancer Treatment: Disruption of Myc-Max Heterodimerization. Int J Clin Pharmacol Pharmacother 1: 114. doi: http://dx.doi.org/10.15344/2016/ijccp/114

Page 3 of 4

new molecule contains a bis-benzamide core via synthetic a-helix mimetics. JKY-2-169 perturbs Myc-Max heterodimer binding to approved E-box DNA sequences without producing protein-protein dissociation. The resulting inhibition of Myc in proliferating cells, both in vitro and in vivo, leads to cell cycle arrest and apoptosis. Compared with previous Myc inhibitors, JKY-2-169 does not disrupt Myc-Max heterodimers in cells, but specifically inhibits a Myc-dependent reporter. Consequently, JKY-2-169 binds an a-helical region of Myc and decreases the ability of theMyc-Max heterodimer to bind DNA without provoking the dissociation of Myc-Max heterodimers. Several bis-benzamide derivatives exhibited a 2-fold or greater selectivity for Myc-Max heterodimers over Max-Max homodimers with $\mathrm{IC}_{50}$ values of $5.6 \mu \mathrm{M}[18]$.

Vogt et al. isolated and validated the first nonpeptidic Myc-Max inhibitors from an in-house peptidomimetics library using an ELISA and electrophoretic mobility-shift assay (EMSA). Among these inhibitors, IIA6B17 containing an isoindoline scaffold antagonized the Myc-Max/DNA ternary complex with an ELISA $\mathrm{IC}_{50}$ value of $125 \mu \mathrm{M}$ and EMSA IC I0 $_{50}$ value of $40 \mu \mathrm{M}$ [19]. Moreover, IIA6B17 hindered Myc-induced oncogenic transformation of chicken embryo fibroblast (CEF) cells $\left(\mathrm{IC}_{50}=20 \mu \mathrm{M}\right)$. In addition, the lead molecules developed by Vogt et al. was discovered to inhibit c-Jun, inferring that their mechanisms might involve the bHLH-ZIP domain that is found in many transcription factors. It is possible that these compounds restrain the oncogenic activity of Myc indirectly by stabilizing MycMax homodimers and thereby diminishing the concentration of Max accessible for heterodimerization by Myc [20]. Together with Boger et al., Vogt and colleagues substituted the isoindoline-5,6-dicarboxylate scaffold of IIA6B17 to a pyrrolidine-3,4-dicarboxylate group (labeled mycmycin-1 and mycmycin-2), resulting in inhibition of Myc-induced oncogenic transformation in CEF cells. The second generation of Myc inhibitors designed by this group is 10 -fold more potent than the parent compound, IIA6B17. Notably, mycmycin-1 and mycmycin-2 do not inhibit the oncogenic transcription factor c-Jun.

Janda, Vogt, and colleagues developed a compound library based on a reciprocal hydrophobic and planar naphthalene scaffold. Forty small molecules were screened from 285 compounds through a fluorescent resonance energy transfer screening assay. Among the 40 screened molecules, 4 effectively inhibited Myc-Max/DNA binding, including NY2276 and NY2267, with $\mathrm{IC}_{50}$ values in the range of $17-36 \mu \mathrm{M}$. NY2276 has an $\mathrm{IC}_{50}$ value of $17 \mu \mathrm{M}$ in an in vitro assay; however, this compound has weak antagonistic effects on Mycinduced oncogenic transformation in cell culture [21]. Recently, these researchers identified compound KJ-Pyr-9 in a Kröhnke pyridine library using a fluorescent polarization screen. KJ-Pyr-9 is not acutely toxic at concentrations as high as $10 \mathrm{mg} / \mathrm{kg}$ and penetrates the bloodbrain barrier. In addition, KJ-Pyr-9 occurs at higher concentrations in brain tissue than in the blood after $4 \mathrm{~h}$. Furthermore, nude mice treated daily with $10 \mathrm{mg} / \mathrm{kg} \mathrm{KJ}-\mathrm{Pyr}-9$ by i.p. injection for one month expressed MDA-MB-231 cells. Tumor volume in the KJ-Pyr-9-treated mice did not notably increase and body weights were unchanged [22]

Berg et al. utilized a fluorescent polarization assay to screen a library of 17,000 chemicals in order to discover a Myc inhibitor, Mycro 1, which disrupts the binding between Myc-Max and DNA with an $\mathrm{IC}_{50}$ value of $72 \mu \mathrm{M}$. Mycro 1 is selective for Myc-Max heterodimers over c-Jun-c-Fos heterodimers and inhibits proliferation of a diverse number of cell lines, including the breast cancer cell line MCF-7. In a recent progress report, Berg et al. reported the discovery of Mycro3, a pyrazolo[1,5-a]pyrimidine scaffold that inhibits both Myc-Max dimerization and DNA-binding with good selectivity [23].
Henriksson et al. identified Myc pathway response agents (MYRA), which are small molecules that inhibit Myc-induced cellular transformation[24]. Interestingly, MYRA-A and MYRA-B have different inhibitory effects on the DNA-binding activity of MycMax. MYRA-A hampers the DNA binding of Myc-Max and MntMax heterodimers in a dose-dependent manner, but has no effect on DNA binding of the E-box-binding transcription factor, USF. In contrast, MYRA-B showed no effects at a concentration of $400 \mu \mathrm{M}$, as determined by EMSA. MYRA-A might conceivably discriminate the Myc protein from other E-box-binding proteins; however, MYRA-B potentially acts through effects on variant E-box promoters by interacting with other transcriptional factors that bind Myc, by interfering with adaptor proteins, or by an indirect mechanism [24].

\section{Challenge}

Our understanding of mechanisms involved in direct interruption of Myc-Max heterodimerization or Myc-Max/DNA complexation using small molecules has been advancing rapidly over the past several years. Several research groups have identified small molecules that have good inhibitory effects on the Myc-Max/DNA complex, in both in vitro and in vivo models. Experimental data suggest that small molecules have the potential to be advanced into therapeutic agents for customized cancer treatment. However, we still need to overcome significant barriers in order to obtain highly specific and active anticancer drugs. The development of small molecules using rational drug design, along with functionalization to interrupt the hot spot between Myc-Max and Myc-Max/DNA could result in the development of effective therapeutic drugs to treat cancers.

\section{Competing Interest}

The authors declare that they have no competing interests.

\section{Funding}

This work was supported by Korea Research Institute of Chemical Technology (Grant No. KK-1507-C14 and KK-1607-C09).

\section{References}

1. Chen BJ, Wu YL, Tanaka Y, Zhang W (2014) Small molecules targeting c-Myc oncogene: promising anti-cancer therapeutics. Int J Biol Sci 10: 1084-1096.

2. Blackwood EM, Eisenman RN (1991) Max: a helix-loop-helix zipper protein that forms a sequence-specific DNA-binding complex with Myc. Science 251: 1211-1217.

3. Nair SK, Burley SK (2003) X-ray structures of Myc-Max and Mad-Max recognizing DNA. Molecular bases of regulation by proto-oncogenic transcription factors. Cell 112: 193-205.

4. Lin CY, Loven J, Rahl PB, Paranal RM, Burge CB, et al. (2012) Transcriptional amplification in tumor cells with elevated C-Myc. Cell 151: 56-67.

5. Adhikary S, Eilers M (2005) Transcriptional regulation and transformation by Myc proteins. Nat Rev Mol Cell Biol 6: 635-645.

6. Zhang W, Kater AP, Widhopf GF, Chuang HY, Enzler T, et al. (2010) B-cell activating factor and $\mathrm{V}$-Myc myelocytomatosis viral oncogene homolog (c-Myc) influence progression of chronic lymphocytic leukemia. Proc Natl Acad Sci U S A 107: 18956-18960.

7. Lawlor ER, Soucek L, Brown-Swigart L, Shchors K, Bialucha CU, et al. (2006) Reversible kinetic analysis of Myc targets in vivo provides novel insights into Myc-mediated tumorigenesis. Cancer Res 66: 4591-4601.

8. Sodir NM, Swigart LB, Karnezis AN, Hanahan D, Evan GI, et al. (2011) Endogenous Myc maintains the tumor microenvironment. Genes Dev 25: 907-916. 
Citation: Kim H, Yoo M, Jung KY (2016) A Promising but Challenging Strategy for Cancer Treatment: Disruption of Myc-Max Heterodimerization. Int J Clin Pharmacol Pharmacother 1: 114. doi: http://dx.doi.org/10.15344/2016/ijccp/114

9. Filippakopoulos P, Qi J, Picaud S, Shen Y, Smith WB, et al. (2010) Selective inhibition of BET bromodomains. Nature 468: 1067-1073.

10. Muller S, Filippakopoulos P, Knapp S (2011) Bromodomains as therapeutic targets. Expert Rev Mol Med 13: e29.

11. Sanchez R, Meslamani J, Zhou MM (2014) The bromodomain: from epigenome reader to druggable target. Biochim Biophys Acta 1839: 676685.

12. Yin X, Giap C, Lazo JS, Prochownik EV (2003) Low molecular weight inhibitors of Myc-Max interaction and function. Oncogene 22: 6151-6159.

13. Wang H, Hammoudeh DI, Follis AV, Reese BE, Lazo JS, et al. (2007) Improved low molecular weight Myc-Max inhibitors. Mol Cancer Ther 6 : 2399-2408.

14. Follis AV, Hammoudeh DI, Wang H, Prochownik EV, Metallo SJ (2008) Structural rationale for the coupled binding and unfolding of the c-Myc oncoprotein by small molecules. Chem Biol 15: 1149-1155.

15. Yap JL, Wang H, Hu A, Chauhan J, Jung KY, et al. (2013) Pharmacophore identification of c-Myc inhibitor 10074-G5. Bioorg Med Chem Lett 23: 370374.

16. Wang H, Chauhan J, Hu A, Pendleton K, Yap JL, et al. (2013) Disruption of Myc-Max heterodimerization with improved cell-penetrating analogs of the small molecule 10074-G5. Oncotarget 4: 936-947.

17. Chauhan J, Wang H, Yap JL, Sabato PE, Hu A, et al. (2014) Discovery of methyl 4'-methyl-5-(7-nitrobenzo[c][1,2,5]oxadiazol-4-yl)-[1,1'-biphenyl]3-carboxylate, an improved small-molecule inhibitor of c-Myc-max dimerization. Chem Med Chem 9: 2274-2285.

18. Jung KY, Wang H, Teriete P, Yap JL, Chen L, et al.(2015) Perturbation of the c-Myc-Max protein-protein interaction via synthetic alpha-helix mimetics. $J$ Med Chem 58: 3002-3024.

19. Berg T, Cohen SB, Desharnais J, Sonderegger C, Maslyar DJ, et al. (2002) Small-molecule antagonists of Myc/Max dimerization inhibit Myc-induced transformation of chicken embryo fibroblasts. Proc Natl Acad Sci U S A 99: 3830-3835.

20. Lu X, Vogt PK, Boger DL, Lunec J (2008) Disruption of the MYC transcriptional function by a small-molecule antagonist of MYC/MAX dimerization. Oncol Rep 19: 825-830.

21. Xu Y, Shi J, Yamamoto N, Moss JA, Vogt PK, et al. (2006) A credit-card library approach for disrupting protein-protein interactions. Bioorg Med Chem 14: 2660-2673.

22. Hart JR, Garner AL, Yu J, Ito Y, Sun M, et al. (2014) Inhibitor of MYC identified in a Krohnke pyridine library. Proc Natl Acad Sci U S A 111: 12556-12561.

23. Kiessling A, Wiesinger R, Sperl B, Berg $T$ (2007) Selective inhibition of c-Myc/Max dimerization by a pyrazolo[1,5-a]pyrimidine. Chem Med Chem 2: $627-630$.

24. Mo H, Henriksson M (2006) Identification of small molecules that induce apoptosis in a Myc-dependent manner and inhibit Myc-driven transformation. Proc Natl Acad Sci U S A 103: 6344-6349. 